\title{
Electroretinographic findings in transplant chorioretinopathy
}

This article was published in the following Dove Press journal:

Clinical Ophthalmology

10 July 2010

Number of times this article has been viewed

\author{
Brian T Chan-Kai' \\ Steven Yeh $^{2}$ \\ Richard G Weleber ${ }^{2}$ \\ Peter J Francis ${ }^{2}$ \\ Grazyna Adamus ${ }^{2}$ \\ $S$ Robert Witherspoon ${ }^{3}$ \\ Andreas K Lauer ${ }^{1}$ \\ 'Cullen Eye Institute, Baylor College \\ of Medicine, Houston, Texas; ${ }^{2}$ Casey \\ Eye Institute, Oregon Health and \\ Science University, Portland, Oregon; \\ ${ }^{3}$ Retina Institute of Texas, Dallas, \\ Texas, USA
}

Aim: Transplant chorioretinopathy is a rare complication following solid organ or bone marrow transplantation and can result in severe vision loss. This series presents electroretinogram (ERG) results in patients with this condition.

Methods: Patients who presented with bilateral vision loss following bone marrow or solid organ transplantation were identified. A complete ophthalmologic examination, fundus photography, and fluorescein angiography (FA) were performed. Full-field ERG was obtained in all patients and a multifocal ERG (mfERG) was obtained in two patients.

Results: Four patients were identified. All patients had bilateral vision loss and displayed a characteristic pattern of mottled hyperfluorescence on FA. Three patients developed progressive vision loss ranging from 20/60 to hand motions whereas one retained 20/40 vision. All patients exhibited moderate to severe cone dysfunction, while the degree of rod abnormalities was varied. Two patients with severe cone dysfunction showed mild clinical changes initially, but later developed progressive vision loss and chorioretinal atrophy.

Conclusion: Transplant chorioretinopathy patients undergoing ERG testing show cone dysfunction with a variable degree of rod dysfunction. ERG abnormalities preceded the visual acuity and clinical changes in two patients, suggesting that ERG may be a helpful predictor of the clinical course in this rare disease.

Keywords: transplant, chorioretinopathy, electroretinogram, ERG, mfERG

\section{Introduction}

Ophthalmic complications associated with bone marrow or solid organ transplantation include a number of anterior segment and posterior segment findings. Transplant-related chorioretinopathy features vasculopathy of the choroid and retina, retinal pigment epithelial (RPE) atrophy, and serous retinal detachment, all of which may result in visual loss. ${ }^{1-9}$ Although other authors have corroborated initial observations of this condition, an understanding of the precise mechanisms underlying this condition is incomplete. In some instances, complaints of decreased vision may precede ophthalmoscopic findings.

Retinal electrophysiologic testing is a useful technique detecting and categorizing retinal dysfunction, and is particularly helpful in patients who do not display discernible pathologic changes using ophthalmoscopy, or other vascular or structural modalities of retina imaging.

To characterize this rare and potentially visually debilitating entity further, we describe a series of four patients with transplant-associated chorioretinopathy, representative ERG features, and their long-term follow-up.
Correspondence:Andreas K Lauer

Casey Eye Institute, Oregon Health and Science University, 3375 SW Terwilliger Blvd, Portland, OR 97239, USA

Tel +l 5034948093

Fax +I 5034947233

Email lauera@ohsu.edu 


\section{Methods}

Prior to performing a retrospective case review of the affected patients, approval from the Oregon Health and Science University institutional review board was obtained in compliance with the Health Insurance Portability and Accountability Act of 1996. The records of four patients with transplant chorioretinopathy were reviewed. All patients had previously undergone complete ophthalmologic examination, fundus photography, and fluorescein angiography.

A full-field electroretinogram (ERG) was performed using protocols that are consistent with the guidelines set out by the International Society for Clinical Electrophysiology of Vision standards. ${ }^{10}$ As a reference, normal full-field electrophysiologic waveforms are included in Figure 1A. The vertical marks denote the stimulus flash. In brief, the parameters measured were: a $30 \mathrm{~Hz}$ flicker (in a light-adapted patient, cone responses are evoked by a stimulus flickering at $30 \mathrm{~Hz}$ ); a photopic single flash (in a light-adapted patient, a bright white flash stimulus evokes primarily a cone-mediated response, ie, the so-called "cone-ERG"); scotopic oscillatory potentials (OP; in a darkadapted patient, a variable response in the positive deflection, felt to arise from amacrine cells, and these responses are diminished in eyes with ischemia); and scotopic single flash (in the dark-adapted eye is maximal response, a bright single white flash stimulus and in a dark-adapted eye, a rod-isolated response is obtained that occurs after a darkadapted patient receives dim white and/or a blue flash that

\section{A Full -field ERG}

$30 \mathrm{~Hz}$ Flicker

$34 \mathrm{~cd} / \mathrm{m}^{2}$ Background

No Background

Photopic single flash white $+0.6 \log \mathrm{cd}-\mathrm{s} / \mathrm{m}^{2}$

Scotopic OPs $(100-300 \mathrm{~Hz})$ white $+0.6 \log \mathrm{cd}-\mathrm{s} / \mathrm{m}^{2}$

Scotopic single flash

white $+0.6 \log \mathrm{cd}-\mathrm{s} / \mathrm{m}^{2}$

Blue flash $(\lambda<470 \mathrm{~nm})$

\section{Normal}
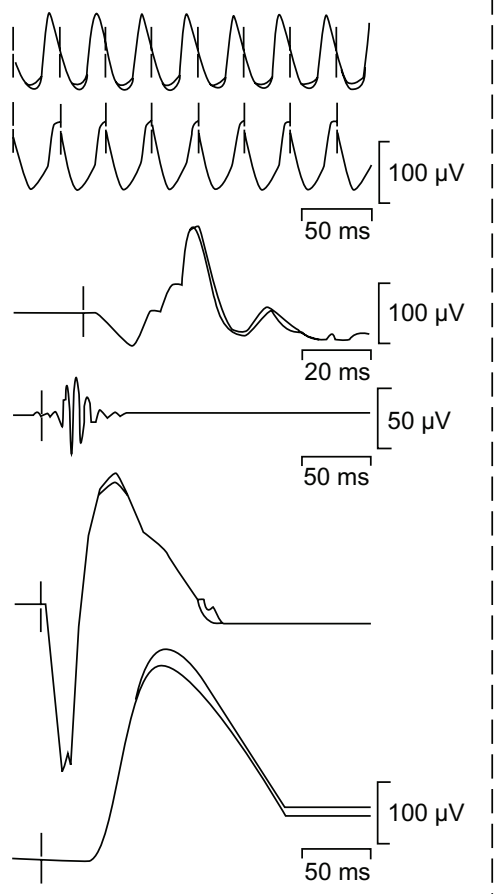

B mfERG

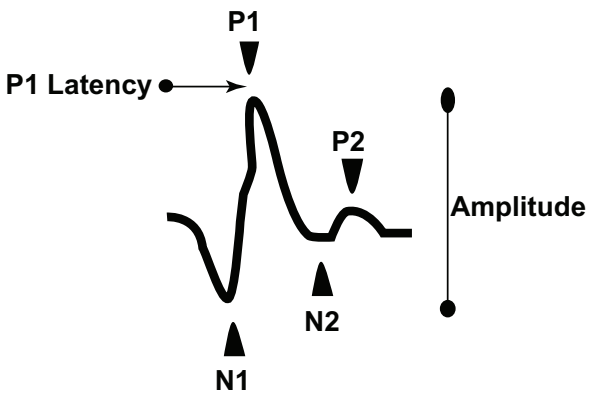

Nanovolts (nV)

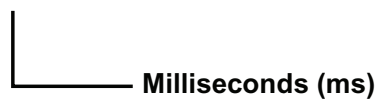

Figure I Representative normal waveforms full-field and multifocal electroretinograms (mfERG) are presented. A) The normal full-field electroretinogram (ERG): The vertical marks denote the stimulus flash. In brief, the following parameters were measured. $30 \mathrm{~Hz}$ flicker: In a light-adapted patient, cone responses are evoked by a stimulus flickering at $30 \mathrm{~Hz}$. Photopic single flash: In a light-adapted patient, a bright white flash stimulus evokes primarily a cone-mediated response, the so-called "cone-ERG". Scotopic oscillatory potentials (OPs): In a dark-adapted patient, a variable response in the positive deflection felt to arise from amacrine cells. These responses are diminished in eyes with ischemia. The scotopic single flash: In the dark-adapted eye, is maximal response, a bright single white flash stimulus. In a dark-adapted eye, a rod-isolated response is obtained that occurs after a dark-adapted patient received dim white and or blue flash that is below cone threshold. In so doing, the resulting waveform is almost exclusively a b-wave. B) The normal mfERG: The typical waveform of the primary mfERG response is a biphasic wave with an initial negative deflection followed by a positive peak. There may be a second negative deflection after the peak. The preferred designation is to label these three peaks NI, PI, and N2, respectively. There similarity in this waveform with the conventional ERG. Amplitude is measured in nanovolts and time in milliseconds. The data reporting consists of a trace array, ring averages (a concentric ring of averages), and topographic representation of amplitudes and PI latencies (implicit times). 
is below the cone threshold, and in so doing, the resulting waveform is almost exclusively a b-wave).

Multifocal ERG (mfERG) was performed in two patients using the Veris system (EDI, San Mateo, CA) with a protocol that used 103 hexagons, Burian-Allen bipolar electrodes, dilated pupils, refraction adjusted to the $40 \mathrm{~cm}$ test distance, band-pass of 10-300 Hz, and a testing time of eight minutes divided into 60-second segments. ${ }^{11}$ In brief, $\mathrm{mfERG}$ is a technique for assessing the local electrical response from numerous regions of the posterior retina. The typical waveform of the primary mfERG response is a biphasic wave with an initial negative deflection followed by a positive peak (Figure 1B). There may be a second negative deflection after the peak. The preferred designation is to label these three peaks N1, P1, and N2, respectively. There may be similarity in this waveform with the conventional ERG. Amplitude is measured in nanovolts and time in milliseconds. The data reporting consists of a trace array, ring averages (a concentric ring of averages) and topographic representation of amplitudes and P1 latencies (implicit times).

\section{Results}

Four patients were identified. Underlying disease, transplant history, immunosuppressive regimen, presenting visual acuity, visual acuity at final follow-up, and other patient data are summarized in Table 1. The mean age of the patients was 43 (range 31-71) years. The mean follow-up time was 5.9 (range 2-13) years. The mean time to presentation was 14 (range 6-24) months post-transplantation, and the mean visual acuity of all affected eyes at presentation was 20/50 (range 20/30-20/80). Three patients developed progressive vision loss to hand motions ranging from 20/60. One patient remained stable clinically and retained $20 / 40$ visual acuity over the 2.5 year follow-up period.

\section{Case I}

A 71-year-old male with a history of end-stage heart failure who underwent cardiac transplantation 10 years prior to presentation was seen for gradual, bilateral vision loss and nyctalopia starting 24 months after transplantation. His immunosuppressive regimen consisted of cyclosporine $150 \mathrm{mg}$ twice daily and prednisone $7.5 \mathrm{mg}$ once daily. Best corrected vision was 20/80 in the right eye and 20/40 in the left. Dilated examination revealed areas of mottled pigmentation atrophy and hyperpigmentation throughout the posterior pole. No retinal vascular abnormalities were present, and the peripheral retina was unremarkable. Fluorescein angiography revealed mottled hypo- and hyperfluorescence with multiple areas of focal leakage. Areas of nonperfusion were absent (Figure 2). A full-field ERG revealed subnormal rod and cone responses with prolonged implicit times when compared with normal. Light-adapted cone amplitudes ( $30 \mathrm{~Hz}$ flicker, photopic single flash) were significantly lower in the right eye and mildly subnormal in the left eye, with prolonged implicit times in both eyes (Figure 3). The patient's vision declined progressively

Table I Summary of four identified patients, their underlying disease, transplant history, immunosuppressive regimen, presenting visual acuity, visual acuity at final follow-up, and summary of electroretinogram results

\begin{tabular}{|c|c|c|c|c|c|c|}
\hline $\begin{array}{l}\text { Age } \\
\text { (years) }\end{array}$ & Gender & $\begin{array}{l}\text { Transplant } \\
\text { history }\end{array}$ & Immunosuppressant & $\begin{array}{l}\text { Snellen VA } \\
\text { right left }\end{array}$ & $\begin{array}{l}\text { Snellen VA last } \\
\text { follow-up right left }\end{array}$ & ERG/mfERG \\
\hline 71 & $M$ & $\begin{array}{l}\text { Cardiac } \\
\text { transplant }\end{array}$ & $\begin{array}{l}\text { Prednisone } 7.5 \mathrm{mg} \text { daily } \\
\text { Cyclosporin } 300 \mathrm{mg} \\
\text { twice daily }\end{array}$ & $\begin{array}{l}20 / 80 \\
20 / 40\end{array}$ & $\begin{array}{l}\text { HMCF } 2 \mathrm{ft} \\
\text { (two years) }\end{array}$ & $\begin{array}{l}\text { Full-field ERG } \\
\text { Moderately subnormal amplitudes } \\
\text { of rod and and dark-adapted cone } \\
\text { responses; prolonged implicit times }\end{array}$ \\
\hline 66 & M & $\begin{array}{l}\text { Bone marrow } \\
\text { transplant }\end{array}$ & $\begin{array}{l}\text { Imuran } 150 \mathrm{mg} \text { daily } \\
\text { Tacrolimus I mg } \\
\text { three times daily } \\
\text { Prednisone } 7.5 \mathrm{mg} \text { daily }\end{array}$ & $\begin{array}{l}20 / 40 \\
20 / 40\end{array}$ & $\begin{array}{l}20 / 40 \\
20 / 40 \\
(2.5 \text { years })\end{array}$ & $\begin{array}{l}\text { Full-field ERG } \\
\text { Moderately decreased rod and cone } \\
\text { amplitudes; prolonged implicit times; } \\
\text { severely subnormal responses of rods } \\
\text { and cones }\end{array}$ \\
\hline 45 & $M$ & $\begin{array}{l}\text { Bone marrow } \\
\text { transplant }\end{array}$ & $\begin{array}{l}\text { Azathioprine } 150 \mathrm{mg} \text { daily } \\
\text { Tacrolimus I mg } \\
\text { three times daily } \\
\text { Prednisone } 7.5 \mathrm{mg} \text { daily }\end{array}$ & $\begin{array}{l}20 / 50 \\
20 / 40\end{array}$ & $\begin{array}{l}\text { CF } 4 \mathrm{ft} \\
20 / 400 \\
(3.3 \text { years })\end{array}$ & $\begin{array}{l}\text { Full-field ERG } \\
\text { Normal rod, severely subnormal cone } \\
\text { amplitudes; prolonged implicit times } \\
\text { mfERG Severely subnormal cone } \\
\text { amplitudes }\end{array}$ \\
\hline 48 & $M$ & $\begin{array}{l}\text { Renal } \\
\text { transplant }\end{array}$ & $\begin{array}{l}\text { Prednisone } 7.5 \mathrm{mg} \text { daily } \\
\text { Cyclosporin } 300 \mathrm{mg} \\
\text { twice daily }\end{array}$ & $\begin{array}{l}20 / 30 \\
20 / 80\end{array}$ & $\begin{array}{l}20 / 60 \\
20 / 200 \\
\text { (14 years) }\end{array}$ & $\begin{array}{l}\text { Full-field ERG } \\
\text { Normal rod amplitudes; moderately } \\
\text { subnormal cone amplitudes } \\
\text { mfERG Severely subnormal cone } \\
\text { amplitudes }\end{array}$ \\
\hline
\end{tabular}

Abbreviations: mfERG, multifocal electroretinogram; VA, visual acuity; ERG, electroretinogram. 


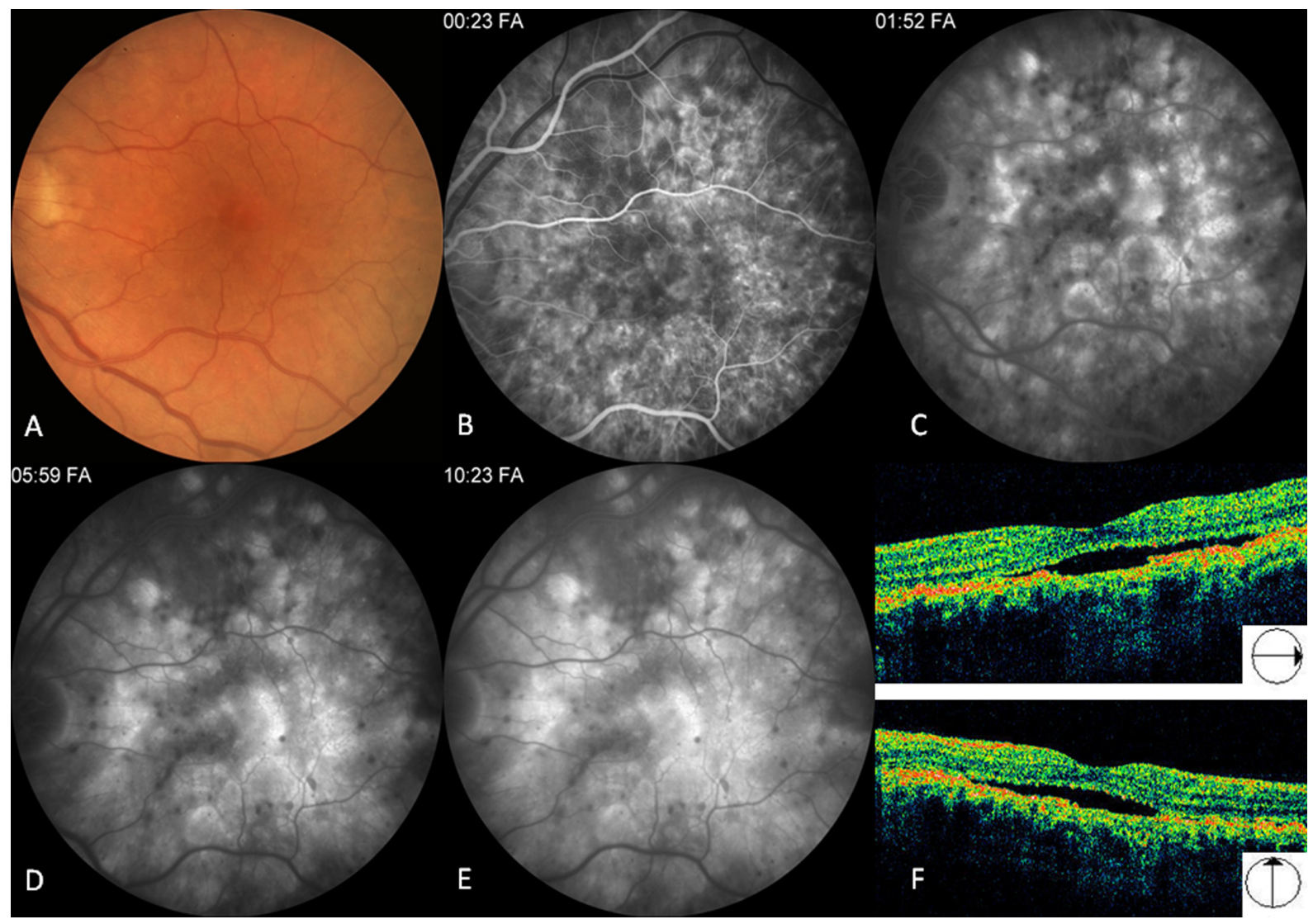

Figure 2 A 7I-year old Caucasian male with a history of cardiac transplantation. A) Color fundus photograph shows retinal pigment epithelial (RPE) changes. B-E) Fluorescein angiogram reveals areas of mottled hypo- and hyperfluorescence with multiple areas of leakage in later frames. F) Time domain optical coherence tomography line scans reveal shallow subfoveal detachments.

over a two-year period, and was hand motions and counting fingers at two feet in the right and left eye, respectively.

\section{Case 2}

A 66-year-old Caucasian male with a history of multiple myeloma who had undergone an autologous bone marrow transplant three years prior to presentation was seen for slowly progressive, bilateral vision loss that began six months following transplantation. His immunosuppressive regimen consisted of prednisone $7.5 \mathrm{mg}$ daily and cyclosporine $150 \mathrm{mg}$ twice daily. Visual acuity was 20/40 in both eyes. Dilated ophthalmoscopy revealed symmetric, mottled pigmentation of the posterior poles. There were shallow serous foveal detachments bilaterally. A full-field ERG demonstrated moderately decreased amplitudes under photopic and scotopic conditions. Implicit times were prolonged. A multifocal ERG showed moderate central cone dysfunction. Two years after his initial presentation, his vision and clinical appearance were unchanged.

\section{Case 3}

A 45-year-old male with a history of multiple myeloma with kappa light chain deposition disease and a prior bone marrow transplant presented for vision loss that began 12 months after transplantation. He previously underwent four cycles of vincristine, adriamycin, and dexamethasone, and had a complete response. Subsequently, he was maintained on prednisone $7.5 \mathrm{mg}$ daily and azathioprine 150 $\mathrm{mg}$ twice daily. His presenting visual acuity was 20/50 in the right eye and 20/40 in the left. Dilated fundus examination showed several small, approximately $150 \mu \mathrm{m}$ white flecks in the outer retina of the posterior pole in both eyes. The retinal vasculature and the periphery were unremarkable. A full-field ERG revealed normal rod function and severely subnormal cone amplitudes. The implicit times were prolonged. Multifocal ERG revealed marked central cone dysfunction. Over three years, he displayed progressive pigmentary atrophy in both eyes (Figure 4). His vision worsened to counting fingers in the right eye and 20/400 in the left.

\section{Case 4}

A 48-year-old Caucasian male with membranoproliferative glomerulonephritis had undergone renal transplantation 


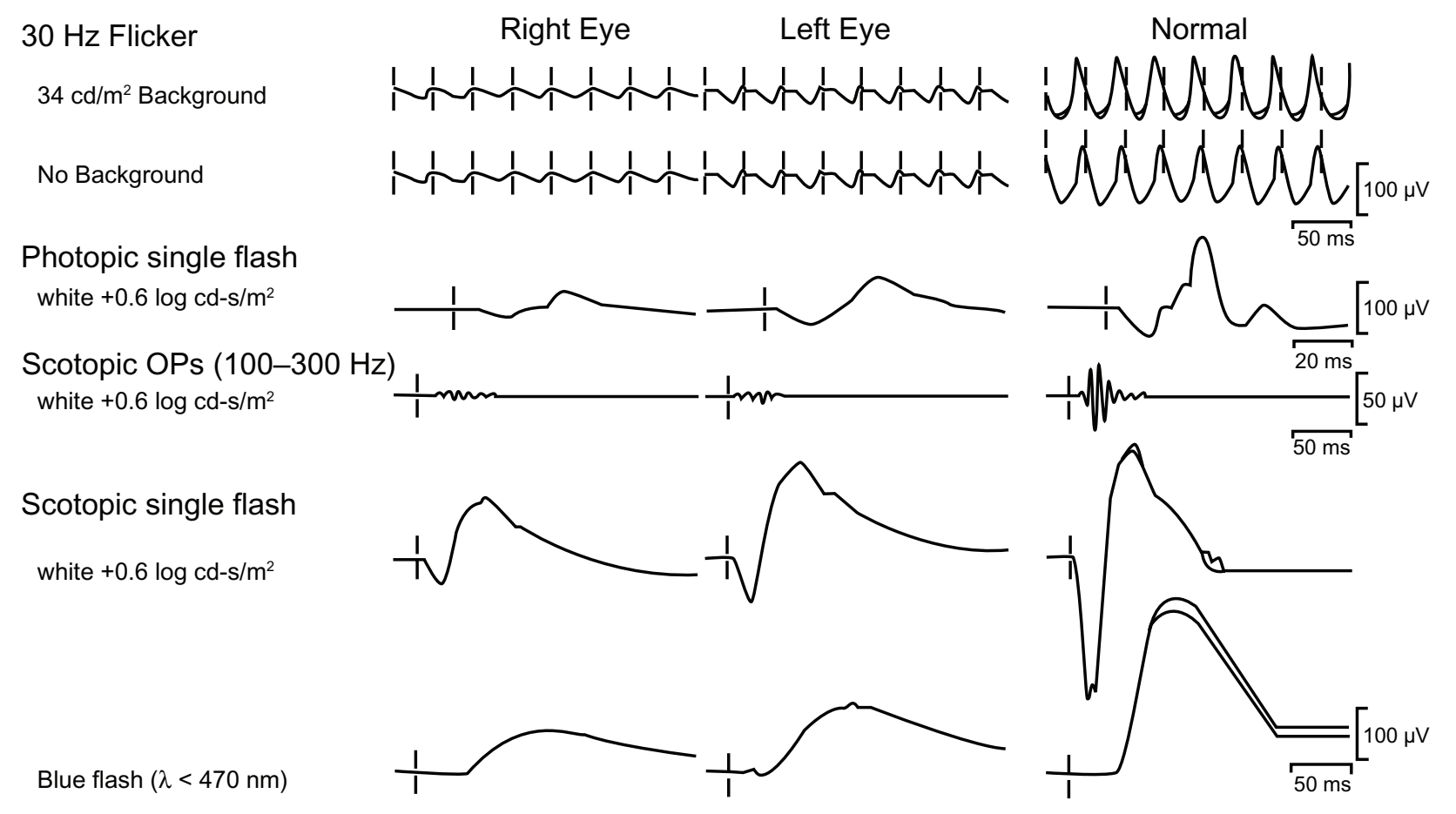

Figure 3 Full-field electroretinogram (ERG) of the patient depicted in Figure I. A control tracing is included for comparison. There are decreased photopic and scotopic amplitudes bilaterally. The implicit times are also prolonged.

15 years prior to presentation. He developed graft rejection, and subsequently received a second transplant seven years prior to presentation. He did well following the second graft, and his immunosuppression consisted of oral cyclosporine $300 \mathrm{mg}$ twice daily and prednisone $7.5 \mathrm{mg}$ daily. Fourteen months following the second transplant, he began to note blurred vision bilaterally. Upon presentation, visual acuity was 20/30 in the right eye and 20/80 in the left. Dilated ophthalmoscopy was significant for a serous detachment of the left macula. The steroids were discontinued and his serous detachment improved over a three-month period. However, his visual acuity remained unchanged. Full-field ERG testing revealed moderate cone dysfunction but normal rod amplitudes. Implicit times were normal. The multifocal ERG demonstrated severe central cone dysfunction in both eyes. Over a 14-year period, he developed progressive pigmentary atrophy in both eyes and his corrected vision worsened to 20/60 in the right eye and $20 / 200$ in the left.

\section{Discussion}

Patients with transplantation-associated chorioretinopathy may present with serous retinal detachments, RPE changes, and retinal microvascular abnormalities. These findings have been described in patients who have undergone renal, heart, combined heart/lung, and bone marrow transplants..$^{1-5,8}$
In our series of four patients, the mean presenting visual acuity was 20/50. Three patients developed progressive vision loss ranging from 20/60 to hand motions. One patient remained stable clinically and retained $20 / 40$ visual acuity over the follow-up period of 2.5 years.

Clinical heterogeneity was observed, with variable degrees of RPE disturbance and photoreceptor dysfunction between patients. In all patients, the degree of RPE disturbance and photoreceptor dysfunction appeared symmetric between fellow eyes. Dilated funduscopic examination findings at presentation ranged from minimal RPE changes in two patients to severe pigmentary atrophy in the other two. Six of eight $(75 \%)$ eyes developed serous retinal detachments at some point during follow-up. Retinal vascular changes were not observed in this series.

We assessed the degree of photoreceptor dysfunction experienced by patients using ERG testing. ERG in all four patients revealed subnormal cone a-wave amplitudes ranging from moderate to severe in all patients. Two of four patients demonstrated moderate rod dysfunction. The implicit times were prolonged in three of four patients. In two patients, the clinical changes and visual acuity were consistent with the severity of the observed ERG abnormalities (cases 1 and 2). Interestingly, the other two patients (cases 3 and 4) presenting with marked cone dysfunction by ERG and exhibited only mild pigmentary changes. Over 

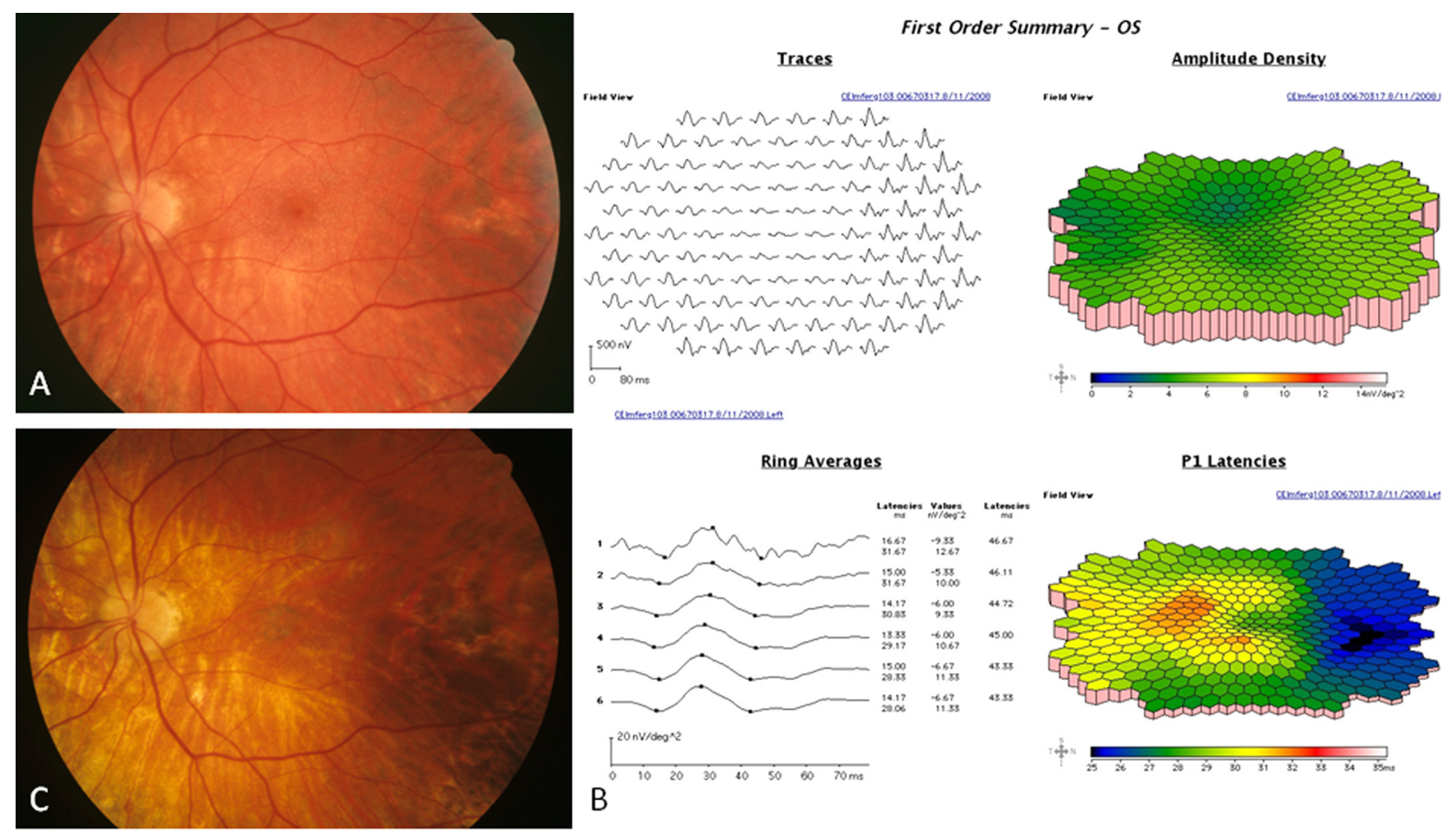

Figure 4 A 45-year-old Caucasian male with a history of bone marrow transplantation following treatment for multiple myeloma. A) On initial presentation, visual acuity was 20/40. Fundus examination was significant for small drusen-like deposits in the macula. B) Multifocal electroretinogram (ERG) performed at presentation was notable for severely decreased central cone amplitudes. C) The trace array reveals central tracings with reduced amplitude and increased implicit times. The topographic amplitude map discloses depressed central amplitude. The ring averages reveal abnormal latencies in the central group of tracings (I and 2 ) compared to the concentric outer groups (5 and 6). The topographic PI latency map disclosed increased implicit times centrally (red and yellow) compared with outer areas. Three years later, the visual acuity has decreased to $20 / 400$, and there is diffuse pigmentary atrophy.

the follow-up period, however, these two patients developed severe bilateral pigmentary atrophy and progressive visual loss.

Although the availability of retinal electrophysiologic testing may be variable, in certain practice environments, organ transplant patients often obtain a portion or all of their care at academic institutions where ERG testing or referral to an appropriate center is generally possible. In instances of decreased vision in these patients, in the absence of discernible findings of retinal ophthalmoscopic pathology, obtaining electrophysiologic testing may help localize the cause of the patient's vision loss.

The presence of subnormal cone dysfunction prior to the development of clinically apparent pigmentary changes suggests a primary retinal abnormality rather than an epitheliopathy with secondary retinal dysfunction. The ERG findings are not able to define the etiology of transplant chorioretinopathy precisely because other causes, such as ischemia and chronic serous detachment, could result in a similar ERG pattern. ${ }^{7,12-18}$ Nevertheless, ERG findings may be of clinical utility in counseling patients because they may serve as an early indicator of a poor clinical course. In the future, with better understanding of the pathophysiology of this condition, detection of ERG dysfunction may serve as an opportunity for modulatory intervention to mitigate imminent vision loss.

In summary, transplant chorioretinopathy is a rare and potentially debilitating complication that may follow solid organ or bone marrow transplantation. In this series of patients, ERG findings revealed severe cone dysfunction with a variable amount of rod dysfunction. These abnormalities may precede the onset of clinically evident changes, as seen in two of four patients in our series. They may also provide some insight into the early changes of this retinal degenerative process and may be a harbinger of future visual loss. Because the spectrum of transplant chorioretinopathy may vary from mild RPE changes to clinically evident serous retinal detachment, ERG testing should be considered in patients with suspicious examination findings. Further studies are needed on the pathogenesis and management of this unusual entity.

\section{Acknowledgments}

This study was supported by an unrestricted grant from Research to Prevent Blindness, New York, and a National Insitutes of Health grant, EY13053. 


\section{Disclosure}

The funding organizations had no part in the preparation of this manuscript.

\section{References}

1. Gass JDM, Slamvotis TL, Full DG, et al. Posterior chorioretinopathy and retinal detachment after organ transplantation. Arch Ophthalmol. 1992;110(12):1717-1722.

2. Gass JDM. Stereoscopic Atlas of Macular Diseases: Diagnosis and Treatment. 4th ed. St. Louis, MO: Mosby; 1997.

3. Fawzi AA, Cunningham ET Jr. Central serous chorioretinopathy after bone marrow transplantation. Am J Ophthalmol. 2001;131(6): 804-805.

4. Fawzi AA, Holland GN, Kreiger AE, et al. Central serous chorioretinopathy after solid organ transplantation. Ophthalmology. 2006;113(5): 805-813.

5. Friberg TR, Eller AW. Serous retinal detachment resembling central serous chorioretinopathy following organ transplantation. Graefes Arch Clin Exp Ophthalmol. 1990;228(4):305-309.

6. Schowengerdt KO, Gajarski RJ Jr. Denfield S. Progressive visual deterioration leading to blindness after pediatric heart transplantation. Tex Heart Inst J. 1993;20(4):299-303.

7. Singh AD, Demirci H, Shields CL, et al. Central serous chorioretinopathy as a complication of postcardiac transplant corticosteroid therapy. Eye. 2003;17(4):522-524.

8. Moon SJ, Mieler WF. Retinal complications of bone marrow and solid organ transplantation. Curr Opin Ophthalmol. 2003;14(6):433-442.

9. Chung H, Kim KH, Kim JG, et al. Retinal complications in patients with solid organ or bone marrow transplantations. Transplantation. 2007;83(6):694-699.
10. Marmor MF, Fulton AB, Holder GE, Miyake Y, Brigell M, Bach M; International Society for Clinical Electrophysiology of Vision. ISCEV Standard for full-field clinical electroretinography (2008 update). Doc Ophthalmol. 2009;118(1):69-77.

11. Marmor MF, Hood DC, Keating D, Kondo M, Seeliger MW, Miyake Y; International Society for Clinical Electrophysiology of Vision. Guidelines for basic multifocal electroretinography (mfERG). Doc Ophthalmol. 2003;106(2):105-115.

12. Walter SH, Bertz H, Gerling J. Bilateral optic neuropathy after bone marrow transplantation and cyclosporin A therapy. Graefes Arch Clin Exp Ophthalmol. 2000;238(6):472-476.

13. Kessler L, Lucescu C, Pinget M, et al. Tacrolimus-associated optic neuropathy after pancreatic islet transplantation using a sirolimus/ tacrolimus immunosuppressive regimen. Transplantation. 2006;81(4): 636-637.

14. Arndt C, Sari A, Ferre M, et al. Electrophysiological effects of corticosteroids on the retinal pigment epithelium. Invest Ophthalmol Vis Sci. 2001;42(2):472-475.

15. Suzuki K, Hasegawa S, Usui T, et al. Multifocal electroretinogram in patients with central serous chorioretinopathy. Jpn J Ophthalmol. 2002; 46(3):308-314.

16. Huang S, Wu D, Jiang F, et al. The multifocal electroretinogram in central serous chorioretinopathy. Ophthalmic Physiol Opt. 2002; 22(3):244-247.

17. Moschos M, Brouzas D, Koutsandrea C, et al. Assessment of central serous chorioretinopathy by optical coherence tomography and multifocal electroretinography. Ophthalmologica. 2007;221(5): 292-298.

18. Avery R, Jabs DA, Wingard JR, et al. Optic disc edema after bone marrow transplantation. Possible role of cyclosporine toxicity. Ophthalmology. 1991;98(8):1294-1301.
Clinical Ophthalmology

\section{Publish your work in this journal}

Clinical Ophthalmology is an international, peer-reviewed journal covering all subspecialties within ophthalmology. Key topics include: Optometry; Visual science; Pharmacology and drug therapy in eye diseases; Basic Sciences; Primary and Secondary eye care; Patien Safety and Quality of Care Improvements. This journal is indexed on

Submit your manuscript here: http://www.dovepress.com/clinical-ophthalmology-journal

\section{Dovepress}

PubMed Central and CAS, and is the official journal of The Society of Clinical Ophthalmology (SCO). The manuscript management system is completely online and includes a very quick and fair peer-review system, which is all easy to use. Visit http://www.dovepress.com/ testimonials.php to read real quotes from published authors. 